\section{The effect of once-daily latanoprost on intraocular pressure and pulsatile ocular blood flow in normal tension glaucoma}

\begin{abstract}
Purpose To determine the effect of once-daily $\mathbf{0 . 0 0 5 \%}$ latanoprost on intraocular pressure (IOP) and pulsatile ocular blood flow (POBF) in patients with normal tension glaucoma (NTG). Methods The diurnal IOP and sitting POBF were determined for 32 eyes of 19 NTG patients after a washout period. The subjects were treated with $0.005 \%$ latanoprost for $3-4$ weeks and the measurements repeated. Statistical analysis was performed using the Wilcoxon signed rank test.

Results Median IOP before and after treatment were 19 and $15 \mathrm{mmHg}$ respectively $(p<0.001)$. The IOP reduction correlated with the initial IOP before treatment $(p<0.01)$ and was accompanied by an increase in median POBF from 656 to $796 \mu \mathrm{l} / \mathrm{min}(p<0.001)$. Conclusions Once-daily treatment with $0.005 \%$ latanoprost provides a significant and stable IOP reduction in the majority of NTG patients after short-term treatment. This is accompanied by a significant increase in POBF.
\end{abstract}

Key words Latanoprost, Normal tension glaucoma, Ocular blood flow

Almost $25 \%$ of patients with typical glaucomatous optic disc and visual field changes have an intraocular pressure (IOP) that is consistently within the statistically normal range. ${ }^{1}$ In this group of patients with normal tension glaucoma (NTG), the optic disc and visual field changes correlate less well with the average or peak IOP. Instead a variety of additional factors appear to make the optic nerve susceptible to damage, such as systemic and ocular vascular disease. ${ }^{2,3}$

Surgery to lower the IOP may prevent or delay progressive field loss in NTG. ${ }^{4}$ However, the fall in IOP with medical therapy is often disappointing and some of the agents used may have an adverse effect on optic nerve perfusion. ${ }^{5,6}$ In this study we evaluated the effect of topical latanoprost on IOP and pulsatile ocular blood flow (POBF) in patients with NTG.

\section{Subjects and methods}

Patients with features of NTG in one or both eyes were enrolled into the study after informed consent had been obtained. The diagnosis of NTG was made on the basis of glaucomatous visual field loss, pathological optic disc cupping or notching, an open drainage angle and an IOP of $22 \mathrm{mmHg}$ or less without topical treatment during previous follow-up and phasing. Patients with previous intraocular surgery, greater than 3 dioptres of myopia and those taking systemic beta-blockers were excluded. The two patients taking other systemic cardiovascular medication were asked to continue this treatment for the duration of the study. When patients had unilateral NTG, only the affected eye was studied. A minimum washout period of 14 days was applied to those patients using topical ocular hypotensive medication.

The diurnal IOP was calculated for each eye as the average of IOP measurements taken at 8 a.m., midday and 4 p.m. Recording was performed with Goldmann tonometry before and after 3-4 weeks of treatment with oncedaily $0.005 \%$ latanoprost at night. Measurement bias was reduced by the use of an opaque shield mounted on the slit lamp to prevent observation of the tonometer scale while adjusting the mires. ${ }^{7}$ After the midday IOP recording on each visit, the POBF was determined in a sitting position after a 5 min rest period, using the OBF Tonograph (OBF Labs., UK). All measurements were performed by the same observer.

The median and $95 \%$ confidence intervals (CI) of the median were calculated for the IOP and POBF values before and after treatment. Significance was determined using the Wilcoxon signed rank test. Pearson's correlation
M. McKibbin

M.J. Menage

Department of Ophthalmology Leeds General Infirmary Leeds, UK

Mr M.J. Menage

Eye Clinic

Clarendon Wing

Leeds General Infirmary

Belmont Grove

Leeds LS2 9NS, UK

Tel: +44(0)113292 2881

Fax: +44 (0)113 2926239

Received: 18 May 1998 Accepted in revised form: 1 October 1998 

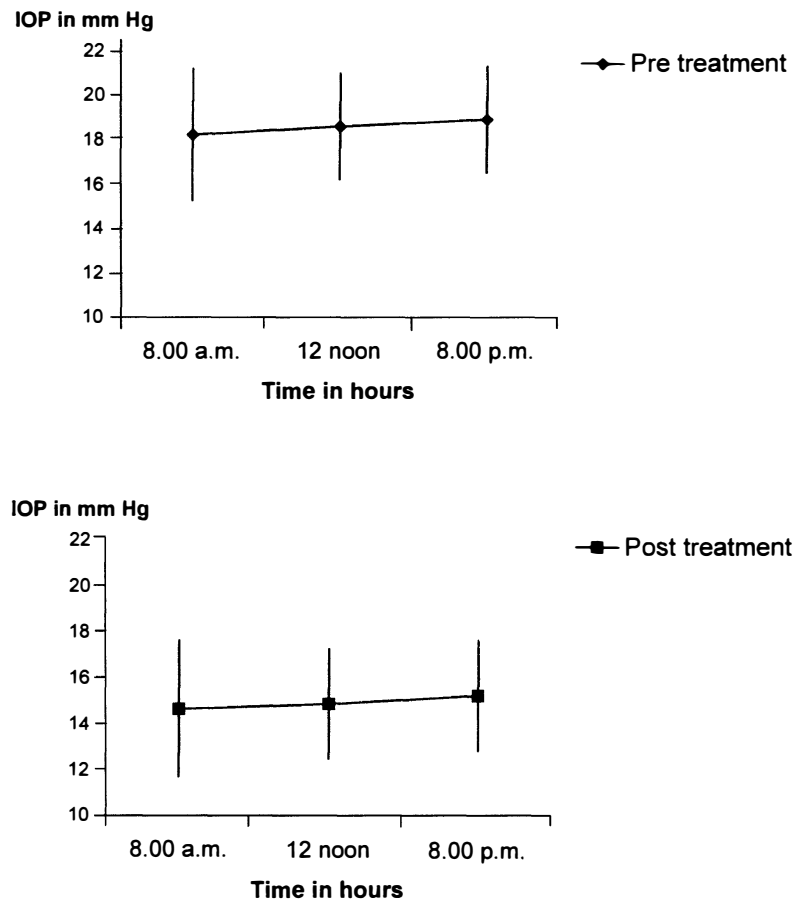

Fig. 1. Average intraocular pressure fluctuation for the 32 eyes studied, before and after treatment with $0.005 \%$ latanoprost.

coefficient was calculated to determine the correlation between the initial IOP and the fall in IOP with treatment.

Ethics committee approval was obtained for this study and verbal and written consent obtained from all subjects.

\section{Results}

Thirty-two eyes from 19 patients were studied. Six of the patients had unilateral NTG. The mean age of the subjects was 70 years and there were 12 women. Twelve of the 19 patients had been using ocular hypotensive medication prior to the study washout period.

The median diurnal IOP at the end of the washout period for the 32 eyes studied was $19.0 \mathrm{mmHg}$ $(C I=17.8-19.8)$. After treatment with once-daily $0.005 \%$ latanoprost, the median IOP was $15.0 \mathrm{mmHg}$ $(\mathrm{CI}=14.4-15.7)$. The median reduction in IOP of $3.5 \mathrm{mmHg}(\mathrm{CI}=3.0-4.2)$ is significant $(p<0.001)$. The IOP fluctuation over the three recording times is shown in Fig. 1. The reduction in IOP obtained with latanoprost treatment correlated with the initial IOP after the washout period. This correlation is significant $\left(r^{2}=0.31\right.$, $p<0.01)$. These data are shown in Fig. 2 .

The median POBF prior to treatment was $656 \mu \mathrm{l} / \mathrm{min}$ $(\mathrm{CI}=588-729)$. After treatment, the median POBF was $796 \mu \mathrm{l} / \mathrm{min}(\mathrm{CI}=697-894)$. This difference is also significant $(p<0.001)$.

\section{Discussion}

In this study, once-daily $0.005 \%$ latanoprost reduced IOP by $18 \%$ in patients with NTG. This was accompanied by an increase in POBF of $21 \%$ after $3-4$ weeks of treatment. No patients withdrew from the study as a result of significant ocular or systemic side-effects.

The average IOP reduction of $18 \%$ is comparable with previous studies relating to the use of latanoprost in NTG. ${ }^{8,9}$ The magnitude of IOP reduction is proportional to the initial IOP (Fig. 2), and this is likely to account for the small variation between the studies. In this study, the reduction was noted after 3-4 weeks of treatment. Although the IOP-lowering effect of latanoprost is maximal within the first week, the IOP reduction is sustained thereafter. ${ }^{10}$ This IOP reduction compares favourably with other forms of medical treatment, particularly given the lack of side-effects reported. ${ }^{5,11}$

IOP reduction $(\mathrm{mm} \mathrm{Hg})$

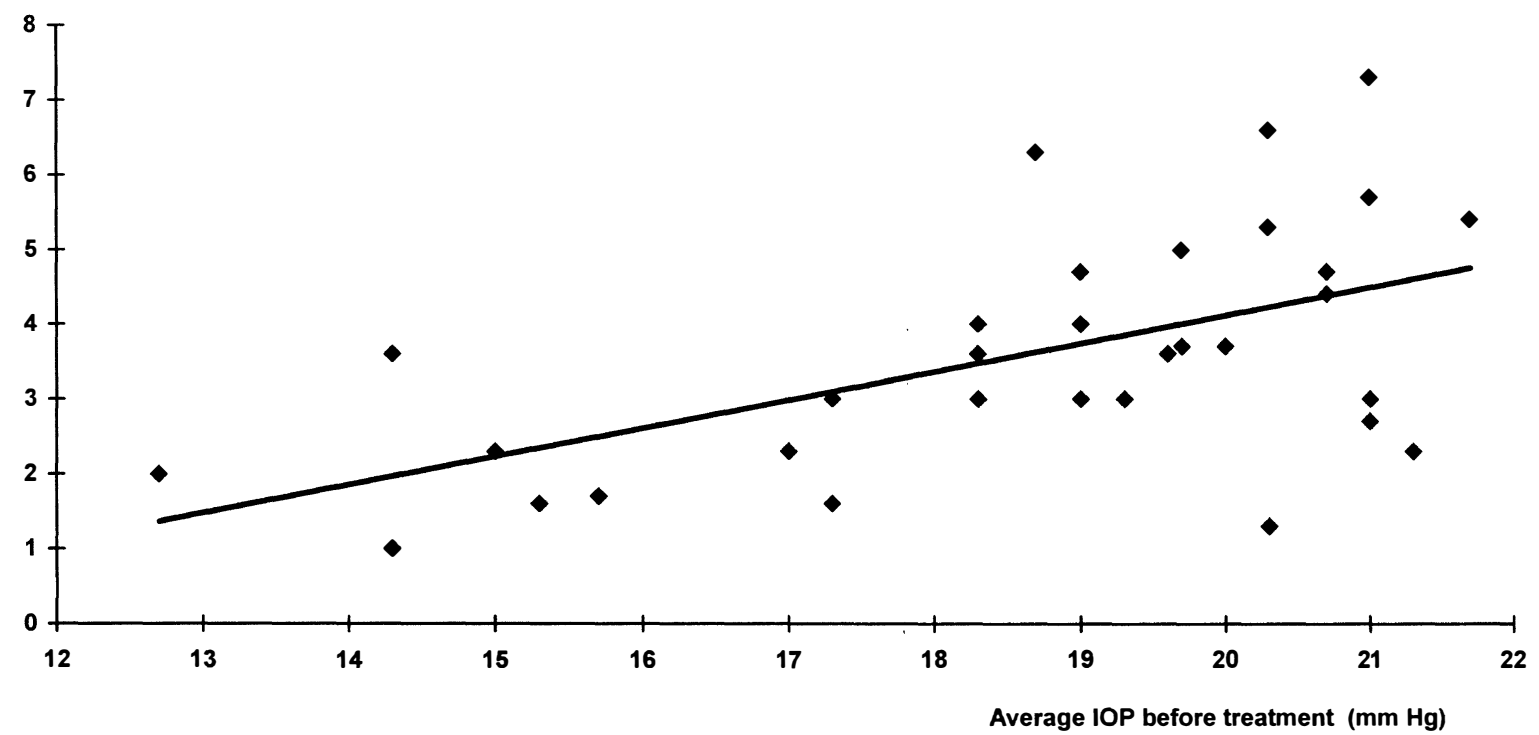

Fig. 2. The intraocular pressure $(I O P)$ reduction correlated with the baseline IOP at the end of the washout period $\left(\mathrm{r}^{2}=0.33\right.$, $\left.\mathrm{p}<0.01\right)$. 
Further IOP reduction may also be possible through the combined use of latanoprost with other ocular hypotensive medication. ${ }^{12}$

A target IOP reduction of $30 \%$ has been advocated previously for the initial management of NTG subjects. ${ }^{13}$ The percentage IOP reduction achieved with latanoprost monotherapy in our study falls short of this target. Given the small numbers in our study, it is difficult to give accurate predictions of the expected effect of treatment, but the results may act as a guide to the likely outcome. An IOP fall in excess of $25 \%$ was achieved for 7 of the 32 treated eyes, but 9 eyes had a reduction of less than $15 \%$. Several possible reasons may account for this variable response to treatment, but we were unable to demonstrate a difference in the clinical parameters such as age, sex or NTG subtype to explain it.

Patients with NTG often show an IOP spike early in the morning. ${ }^{14}$ This morning spike may be beyond the autoregulatory mechanisms of the optic nerve microvasculature and be important in the pathogenesis. ${ }^{13}$ The pressure spike may be apparent only on repeated diurnal IOP measurement. Two patients were excluded from this study when found to have an early morning IOP in excess of $25 \mathrm{mmHg}$, despite previously having normal diurnal IOP recording. Only 5 of the eyes in this study had a morning IOP spike at least $4 \mathrm{mmHg}$ in excess of subsequent recordings. In addition to overall IOP reduction, the smooth and sustained control of IOP is also important in NTG subjects. This may be lacking with aqueous suppressants, which often have little effect during sleep. ${ }^{15}$

Although IOP is important in NTG, it may not be the most important factor in optic nerve damage. Vascular disease and risk factors also appear to be important in the aetiology, together with altered ocular and optic nerve head circulation. ${ }^{2,3}$ POBF values have previously been shown to be reduced in NTG subjects compared with controls. ${ }^{16,17}$ POBF estimation is derived from the ocular pulse, which is proportional to the perfusion pressure and inversely related to vascular resistance. Although this pulse is largely a reflection of choroidal blood flow, the choroidal system is also the main contributor to the optic nerve blood flow. In view of this and the association of reduced POBF with NTG, it appears that POBF measurement may provide an indirect estimation of optic nerve blood flow. $6,16,17$

Treatment with latanoprost had a beneficial effect on POBF in this study, increasing the average flow by $21 \%$ in treated eyes. This increase could be the result of increased perfusion pressure or a change in vascular tone or perfusion. ${ }^{17}$ Previous studies have shown that latanoprost does not have a significant effect on the velocity of the retrobulbar circulation, heart rate or systemic blood pressure, and this feature may enhance its use as therapy in NTG. ${ }^{18-20}$ As a result of these observations we conclude that the increase in POBF seen in this study is the result of an increase in perfusion pressure secondary to the fall in IOP.
Observer error was minimised for Goldmann IOP recording with the use of an opaque shield to prevent simultaneous observation of the tonometer mires and scale. ${ }^{7}$ This is not necessary while recording POBF as the data from consecutive ocular pulses is computeranalysed and a cut-off standard deviation is applied to all recordings. Although the inter-individual variation in POBF is high, the main value in POBF recording is to document a change within individuals over time. ${ }^{21}$ As we have used data from both eyes of some patients, not all the cases in this study are independent. However, sensitivity analysis was performed with data randomly chosen from those patients in whom both eyes were studied and there was no clinically significant difference in either the IOP or POBF results.

This study demonstrates that once-daily treatment with $0.005 \%$ latanoprost provides a significant and stable IOP reduction in NTG patients after short-term treatment. This is accompanied by an increase in POBF. Given the poor effect on IOP in some patients, we would advocate a trial treatment period before commencing long-term therapy. The data from this study are encouraging in the management of NTG, when an adequate IOP reduction is often difficult with medical treatment alone. However, only long-term studies will demonstrate whether these changes are sustained and prevent progressive loss of visual field.

The latanoprost used in this study was supplied by Pharmacia \& Upjohn Limited.

\section{References}

1. Klein BE, Klein R, Sponsel WE, Franke T, Cantor LB, Martone J, Menage MJ. Prevalence of glaucoma: the Beaver Dam Eye Study. Ophthalmology 1992;99:1499-504.

2. Butt Z, McKillop G, O’Brien C, Allan P, Aspinall P. Measurement of ocular blood flow velocity using colour Doppler imaging in low tension glaucoma. Eye 1995;9:29-33.

3. Drance SM, Sweeney VP, Morgan RW. Studies of factors involved in the production of low tension glaucoma. Arch Ophthalmol 1973;89:457-65.

4. Bhandari A, Crabb DP, Poinoosawmy D, Fizke FW, Hitchings RA, Noureddin BN. Effect of surgery on visual field progression in normal tension glaucoma. Ophthalmology 1997;104:1131-7.

5. de Jong N, Greve EL, Hoyng PF, Geijssen HC. Results of a filtering procedure in low tension glaucoma. Int Ophthalmol 1989;13:131-8.

6. Morsman CD, Bosem ME, Lusky M, Weinreb RN. The effect of topical beta-adrenoceptor blocking agents on pulsatile ocular blood flow. Eye 1995;9:344-7.

7. Gillow JT, Aggarwal R. Reducing bias during intraocular pressure measurement. Br J Ophthalmol 1995;79:1057-8.

8. Rulo AH, Greeve EL, Geyssen HC, Hoyng PFJ. Reduction of intraocular pressure with treatment of latanoprost once daily in normal pressure glaucoma patients. Ophthalmology 1996;103:1276-82.

9. Kjellgren D, Douglas G, Mikelberg F, Drance SM, Alm A. The short-time effect of latanoprost in normal pressure glaucoma. Acta Ophthalmol 1995;73:233-6.

10. Camras CB, Alm A, Watson P, Stjernschantz J. Latanoprost, a prostaglandin analog, for glaucoma therapy. Ophthalmology 1996;103:1916-24. 
11. Schulzer M. Intraocular pressure reduction in normal-tension glaucoma patients. The Normal Tension Glaucoma Study Group. Ophthalmology 1992;99:1468-70.

12. Hoyng PFJ, Rulo A, Greve E, Watson P, Alm A. The additive intraocular pressure lowering effect in combined therapy with other ocular hypotensive agents. Surv Ophthalmol 1997;41(Suppl 2):93-8.

13. Kitizawa Y. Unilateral normal tension glaucoma. J Glaucoma 1997;6:50-5.

14. Meier-Gibbons F, Sturmer J, Gloor B. Normal pressure glaucoma: a diagnostic challenge. Klin Monatsbl Augenheilkd 1995;206:157-60.

15. Brubaker RF. Flow of aqueous humour in humans. Invest Ophthalmol Vis Sci 1991;32:3145-66.

16. James $\mathrm{CB}$, Smith SE. Pulsatile ocular blood flow in patients with low tension glaucoma. Br J Ophthalmol 1991;75:466-70.

17. Fontana L, Poinoosawmy P, Bunce CV, O'Brien C, Hitchings R. Pulsatile ocular blood flow in asymmetric normal tension glaucoma and normal subjects. $\mathrm{Br} \mathrm{J}$ Ophthalmol 1998;82:731-6.
18. Nicolela MT, Buckley AR, Walman BE, Drance SM. A comparative study of the effect of timolol and lanatoprost on blood flow velocity of the retrobulbar vessels. Am J Ophthalmol 1996;122:784-9.

19. Drance SM, Crichton A, Mills RP. Comparison of the effect of latanoprost $0.005 \%$ and timolol $0.5 \%$ on the calculated ocular perfusion pressure in patients with normal tension glaucoma. Am J Ophthalmol 1998;125:585-92.

20. Greve EL, Rulo AH, Drance SM, Crichton AC, Mills RP, Hoyng PFJ. Reduced intraocular pressure and increased ocular perfusion pressure in normal tension glaucoma: a review of short term studies with three dose regimens of latanoprost treatment. Surv Ophthalmol 1997;41(Suppl 2):89-92.

21. Yang YC, Hulbert MF, Batterbury M, Clearkin LG. Pulsatile ocular blood flow measurements in healthy eyes: reproducibility and reference values. J Glaucoma 1997;6:175-9. 